\title{
Pembelajaran Konsep Mekanika Fluida Statis Berbantuan Praktikum Virtual dalam Mengembangkan Keterampilan Berpikir Kritis Mahasiswa Calon Guru Matematika
}

\author{
Dede Trie Kurniawan', Nelli Ma'rifat Sanusi ${ }^{2}$, Nurul Ikhsan Kharimah ${ }^{3}$ \\ ${ }^{1,2,3}$ Program Studi Pendidikan Matematika FKIP Unswagati Cirebon
}

\begin{abstract}
This study aimed to analyze the achievement of critical thinking skills of students through virtual lab assisted learning in preservice teachers of mathematics. The method used is weak experiment with the design of the study "one group pretest-posttest design". The research was conducted on the subject for the static fluid level mathematics preservice teachers university sector in the city of Cirebon academic year 2016/2017. The research subjects consisted of one class with the number of samples respectively of 23 preservice teachers of mathematics. The data obtained in this study is data critical thinking skills that include identifying the relevant issues, defines the subject matter, giving the reasons of the experiment, using a strategy logically, doing the things done tentatively, summarized by considering the situation and then decide, answered questions about the facts, report is based on observations, consider the appropriate procedures, involving a bit of conjecture based on those events - events and report experimental generalization. Research hypothesis testing is done by using the t test on the $\mathrm{N}$-gain critical thinking skills after learning to use the virtual lab. The results of data analysis showed critical thinking skills gain of 0.58 (moderate). From this analysis it can be concluded that learning-based virtual lab for preservice teachers of mathematics can significantly improve the critical thinking skills of preservice teachers of mathematics. Besides, in general, the students give a positive response to learning to use the virtual lab.
\end{abstract}

Keywords: Fluid mechanics static, virtual experiment, critical thinking skills, preservice teachers of mathematics

Unswagati Cirebon

Email: dhe3kurniawan@gmail.com
(C)2017 Universitas Islam Negeri Walisongo ISSN: 2088-7868, e-ISSN 2502-5708 


\begin{abstract}
Abstrak
Penelitian ini bertujuan untuk menganalisis ketercapaian keterampilan berpikir kritis mahasiswa melalui pembelajaran berbantuan praktikum virtual pada mahasiswa calon guru matematika. Metode penelitian yang digunakan adalah weak experiment dengan rancangan penelitian "one group pretest-posttest design". Penelitian ini dilaksanakan pada pokok bahasan fluida statis untuk mahasiswa calon guru matematika tingkat I di suatu LPTK swasta kota cirebon tahun ajaran 2016/2017. Subyek penelitian terdiri dari satu kelas dengan jumlah sampel masingmasing sebanyak 23 mahasiswa calon guru matematika. Data yang diperoleh dalam penelitian ini adalah data keterampilan berpikir kritis yang meliputi mengidentifikasi hal yang relevan, mendefinsikan materi subjek, memberikan alasan dari percobaan, menggunakan strategi logis, melakukan hal yang dilakukan secara tentatif, merangkum dengan mempertimbangkan situasi lalu memutuskan, menjawab pertanyaan tentang fakta, melaporkan berdasarkan pengamatan, mempertimbangkan prosedur yang tepat, melibatkan sedikit dugaan berdasrkan peristiwa peristiwa dan melaporkan generalisasi eksperimen. Uji hipotesis penelitian ini dilakukan dengan menggunakan uji t pada $\mathrm{N}$-gain keterampilan berpikir kritis setelah dilakukan pembelajaran menggunakan praktikum virtual. Hasil analisis data menunjukkan $\mathrm{N}$-gain keterampilan berpikir kritis sebesar 0.58 (sedang). Dari analisis ini maka dapat disimpulkan bahwa pembelajaran berbasis praktikum virtual bagi mahasiswa calon guru matematika secara signifikan dapat lebih meningkatkan keterampilan berpikir kritis mahasiswa calon guru matematika. Disamping itu pada umumnya, mahasiswa memberikan tanggapan positif terhadap pembelajaran menggunakan praktikum virtual.
\end{abstract}

Kata kunci: mekanika fluida statis, eksperimen virtual, kemampuan berpikir kritis, mahasiswa calon guru matematika

\title{
PENDAHULUAN
}

Calon guru matematika perlu dibekali pengetahuan dasar sains, salah satunya adalah mata kuliah fisika dasar. Hal ini bertujuan agar mahasiswa dapat menggunakan IPA sebagai cara bernalar (berpikir logis, kritis, sistematis dan objektif) yang dapat digunakan dalam menyelesaikan masalah, baik masalah dalam kehidupan sehari-hari maupun dalam mempelajari berbagai ilmu pengetahuan. Tujuan utama mata kuliah Fisika dasar adalah mengembangkan kemampuan berpikir analisis induktif dan deduktif dengan menggunakan konsep dan prinsip Fisika untuk menjelaskan berbagai peristiwa alam dan menyelesaikan masalah baik secara kualitatif maupun kuantitatif serta dapat mengembangkan keterampilan dan sikap percaya diri Depdiknas (2006). Salah satu konsep penting dalam mata kuliah fisika dasar adalah mekanika. Mekanika merupakan masalah yang cukup berpengaruh dalam perkembangan ilmu fisika. Hal ini dikarenakan mekanika meletakan fondasi dasar dalam ilmu fisika yang mengkaji gerak dalam gejala alam.

Ilmu fisika adalah sebuah ilmu pasti yang mempelajari gejala alam yang bisa diamati dan diukur. Begitu juga dengan mekanika, mekanika merupakan gejala alam 
yang bisa diamati dan diukur. Dengan demikikian konsep dasar ini perlu dibekali pada mahasiswa calon guru matematika sebagai sarana belajar sains untuk mengembangkan proses pembelajaran yang lebih baik, sehingga saat mahasiswa menjadi pengajar di kemudian hari dapat mengaplikasikan dan mengintegrasikan sains terhadap proses pembelajarannya. Transformasi nilai-nilai yang ada dalam tujuan pembelajaran Fisika masih terbatas pada pencapaian nilai/hasil belajar yang setinggi-tingginya dari para mahasiswa, tetapi belum menyentuh aspek pengembangan keterampilan dan kemampuan memecahkan masalah. Hal ini tentu saja dapat membuat mahasiswa calon guru menjadi kurang kritis dalam menghadapi permasalahan dan kurang kreatif dalam mengembangkan keterampilan-keterampilannya.

Berdasarkan studi pendahuluan Kurniawan, (2013) diperoleh hasil bahwa pembelajaran topik mekanika dilakukan oleh dosen dengan metode ceramah, yang tidak disertai praktikum sebagai bentuk aplikasi konsep dikarenakan fasilitas laboratorium kurang memadai yang menyebabkan mahasiswa sulit dalam memahami konsep-konsep mekanika yang diperlukan visualisasi serta aplikasi. Agar konsep-konsep mekanika fluida statis mudah dipahami oleh mahasiswa perlu adanya inovasi-inovasi dalam pembelajaran fisika Salah satu inovasi pembelajaran fisika yaitu dengan pengintegrasian teknologi informasi dan komunikasi dalam bentuk multimedia interaktif berbentuk praktikum virtual.

Keterampilan berpikir kritis termasuk salah satu keterampilan berpikir tingkat tinggi. Keterampilan berpikir kritis secara esensial merupakan keterampilan menyelesaikan masalah (problem solving). Menurut Ennis berpikir kritis adalah kemampuan bernalar dan berpikir reflektif yang diarahkan untuk memutuskan hal-hal yang meyakinkan untuk dilakukan. Costa (1985) menyatakan bahwa berpikir kritis merupakan berpikir masuk akal dan reflektif yang difokuskan pada pengambilan keputusan tentang apa yang dilakukan atau diyakini. Masuk akal berarti berpikir berdasarkan atas fakta-fakta untuk menghasilkan keputusan yang terbaik. Reflektif artinya mencari dengan sadar dan tegas kemungkinan solusi yang terbaik. Selain itu, berpikir kritis pun merupakan dasar untuk belajar mendalam dan terintegrasi. Tanpa berpikir kritis, peserta didik tidak dapat mempelajari sesuatu dengan cara yang lebih bermakna, serta tidak bisa belajar lebih mendalam untuk mengembangkan dan memajukan pemikiran Elder, L, (2007). Pentingnya kemampuan berpikir kritis sehingga 
mahasiswa perlu senantiasa diberikan motivasi dan dirangsang untuk mengembangkan kemampuan berpikir kritis dalam setiap proses pembelajaran. Berdasarkan hal ini maka perlu dilakukan penelitian yang merupakan sebuah strategi untuk mengembangkan kemampuan berpikir kritis mahasiswa. Keterampilan Berpikir kritis ini meliputi mengidentifikasi hal yang relevan, mendefinsikan materi subjek, memberikan alasan dari percobaan, menggunakan strategi logis, melakukan hal yang dilakukan secara tentatif, merangkum dengan mempertimbangkan situasi lalu memutuskan, menjawab pertanyaan tentang fakta, melaporkan berdasarkan pengamatan, mempertimbangkan prosedur yang tepat, melibatkan sedikit dugaan berdasrkan peristiwa - peristiwa dan melaporkan generalisasi eksperimen.

Konsep virtual laboratory menurut Harms (2000) dapat dibedakan menjadi dua konsep utama yaitu: (1) konstelasi percobaan diganti dengan model komputer, berupa simulasi yang mewakili percobaan laboratorium nyata dalam bentuk semirip mungkin disebut virtual lab. (2) eksperimen laboratorium dapat disebut virtual ketika percobaan dikendalikan tidak dengan manipulasi langsung dari peralatan laboratorium, tetapi melalui komputer, yang dihubungkan ke peralatan laboratorium yang sebenarnya melalui jaringan.

Berdasarkan latar belakang diatas penulis berkeinginan untuk meneliti lebih jauh tentang "PEMBELAJARAN KONSEP MEKANIKA FLUIDA STATIS BERBANTUAN PRAKTIKUM VIRTUAL DALAM MENGEMBANGKAN KETERAMPILAN BERPIKIR KRITIS MAHASISWA CALON GURU MATEMATIKA"

\section{METODE PENELITIAN}

Penelitian ini dilaksanakan dengan metode Weak Experiment Fraenkel dan Wallen (2007) yaitu metode penelitian yang menggunakan kelompok sampel perlakuan tanpa sampel kontrol. Penelitian dilakukan pada sekelompok mahasiswa calon guru matematika Universitas Swadaya Gunung Jati.

Pada penelitian ini tidak ada kelas pembanding, mahasiswa diberikan tes awal kemampuan berpikir kritis sebelum perlakuan serta tes akhir kemampuan berpikir kritis setelah perlakuan. Uji coba media praktikum virtual konsep mekanika dilakukan terhadap satu kelompok mahasiswa calon guru matematika semester 1 fakultas pendidikan dan 
keguruan UNSWAGATI.

Penelitian ini menggunakan rancangan One-Group Pretest-Posttest Design Fraenkel dan Wallen (2007). Desain penelitian ini disajikan dalam Tabel 1

Tabel 1. The One-Group Pretest-Posttest Design

\begin{tabular}{|c|c|c|c|}
\hline \multirow{2}{*}{$\begin{array}{c}\text { Kelas } \\
\text { eksperimen }\end{array}$} & $\mathrm{O}$ & $\mathrm{X}$ & $\mathrm{O}$ \\
\cline { 2 - 4 } & Pretest & Treatment & Posttest \\
\hline
\end{tabular}

Fraenkel (2007)

Keterangan :

O1 : Test awal sebelum perlakuan diberikan pada kelompok eksperimen

O2: Test akhir setelah perlakuan diberikan pada kelompok eksperimen

$\mathrm{X} 1$ : Perlakuan dengan pembelajaran praktikum virtual konsep mekanika

Peningkatan keterampilan berpikir kritis dihitung dengan skor N-Gain (Hake, 2004), dan digunakan rumus:

$$
N-\text { Gain }=\frac{\text { skor }_{\text {postes }}-\text { skor }_{\text {pretes }}}{\text { skor }_{\text {maksimum }}-\text { skor }_{\text {pretes }}}
$$

dengan kriteria nilai N-Gain pada Tabel 2

Tabel 2. Kriteria Gain Ternormalisasi (N-Gain)

\begin{tabular}{|l|l|}
\hline N-Gain & Kriteria peningkatan \\
\hline $\mathrm{G}<0,3$ & peningkatan rendah \\
\hline $0,3 \leq \mathrm{G} \leq 0,7$ & peningkatan sedang \\
\hline $\mathrm{G}>0,7$ & peningkatan tinggi \\
\hline \multicolumn{2}{|c}{ (hake, 2004) } \\
\hline
\end{tabular}

Pengolahan data dilakukan dengan menggunakan pogram SPSS for windows versi 16.00. Pengujian normalitas distribusi data dalam penelitian ini dilakukan dengan Kolmogorov-Smirnov. Untuk melihat perbedaan keterampilan berpikir kritis dilakukan pengujian dengan menggunakan uji t.

\section{HASIL DAN PEMBAHASAN}

Pembahasan terhadap Hasil Penelitian berikut dilakukan berdasarkan analisis data dan temuan di lapangan :

\section{Berpikir Kritis Mahasiswa}

Data keterampilan berpikir kritis mahasiswa diperoleh dari Pretest, postest dan NGain Mahasiswa kelas eksperimen dapat dilihat pada gambar 1 dan 2 berikut ini. 


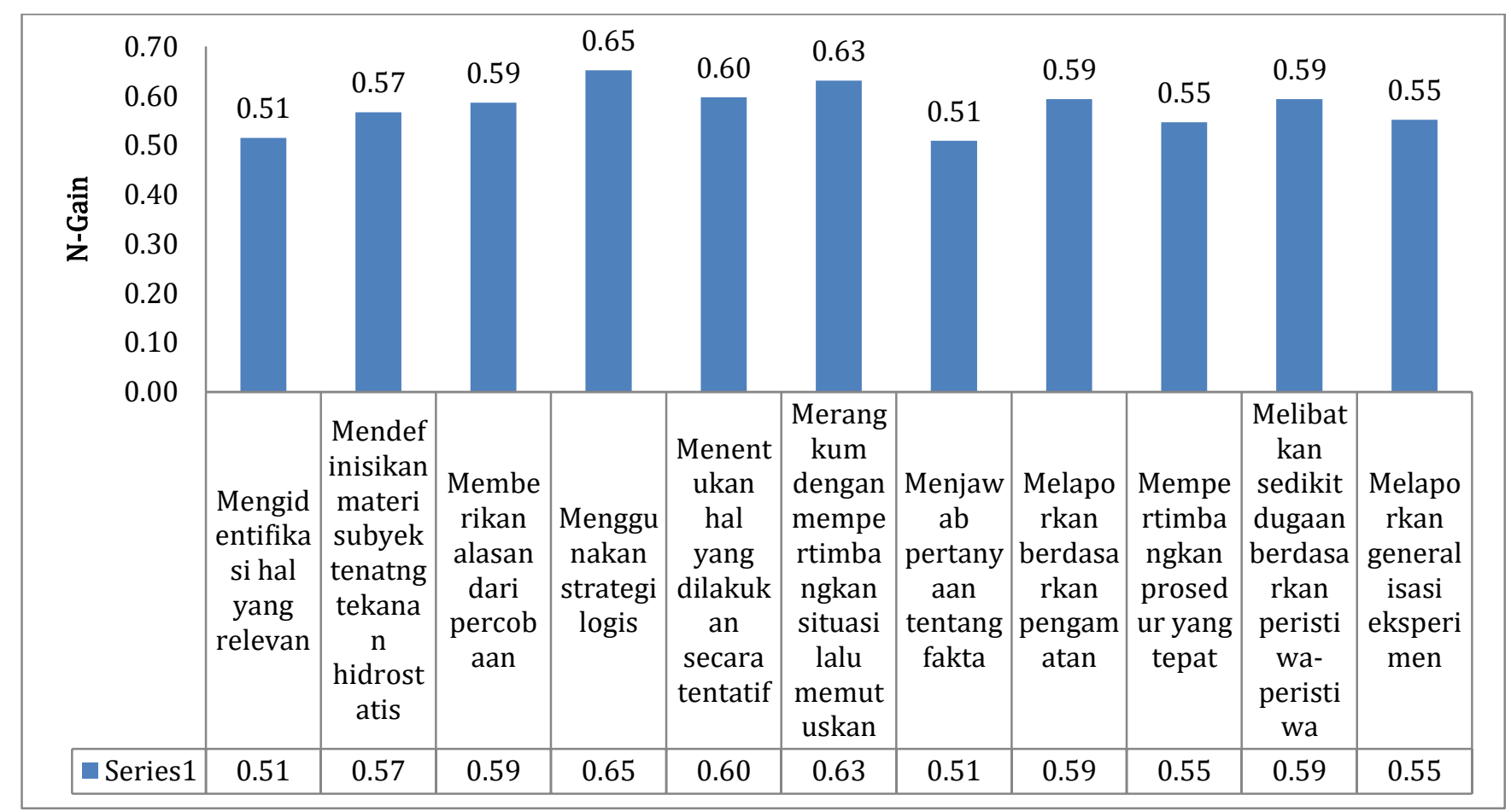

\section{Gambar 1. Pencapaian Keterampilan Berpikir Kritis Mahasiswa Calon Guru Matematika.}

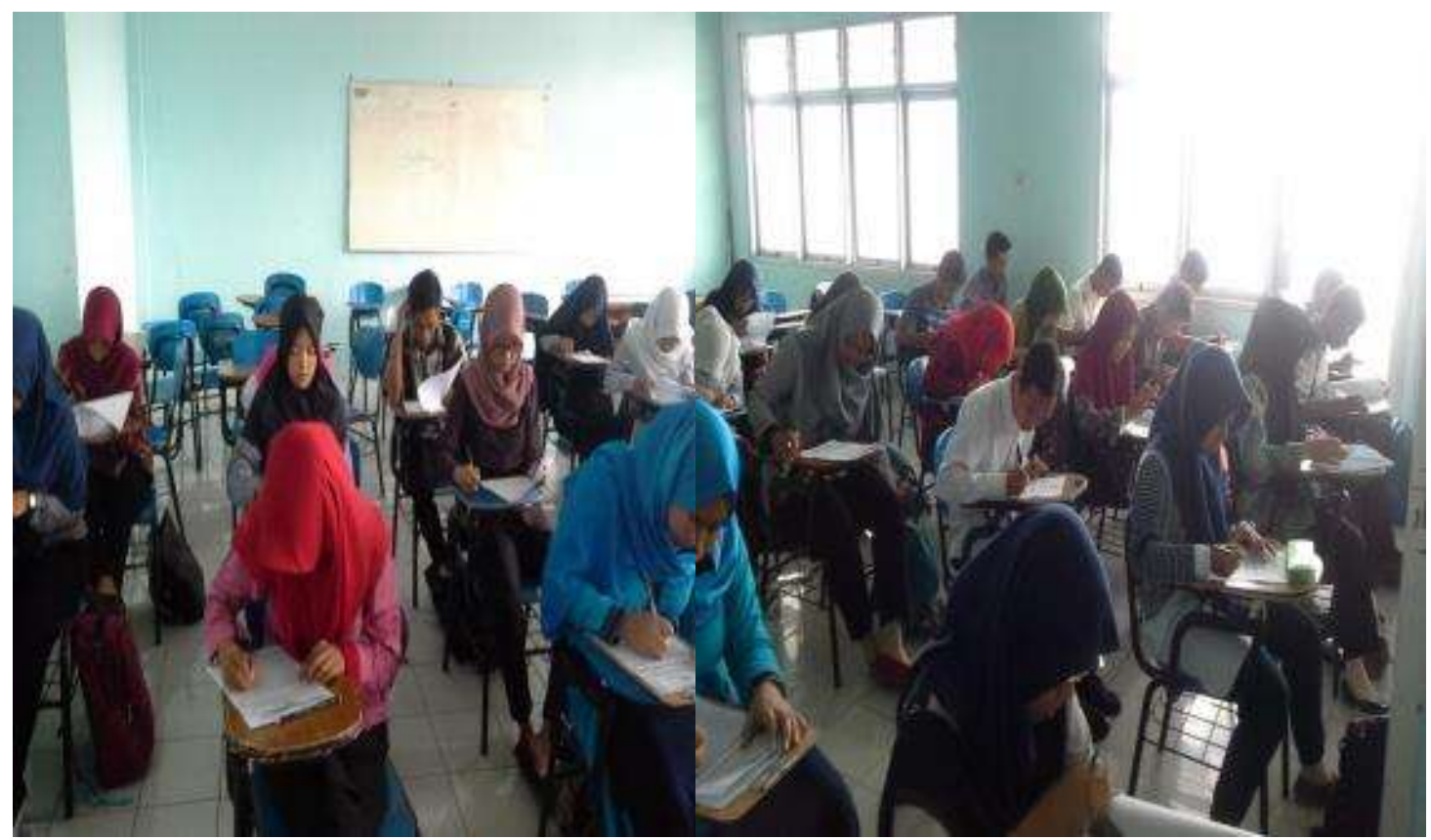

Gambar 2. Tes Keterampilan Berpikir Kritis Konsep Fluida Statis Untuk Mahasiswa calon guru matematika

\section{Implementasi dan Penggunaan Media}

Langkah kerja pengembangan virtual laboratorium meliputi tahap desain yang terdiri atas kegiatan analisis instruksional dan penyusunan garis besar program media perkuliahan. Lalu dilanjutkan dengan penyusunan Flowchart dan storyboard. Dengan 
pedoman flowchart dan storyboard inilah akan disusun media praktikum virtual dengan program aplikasi macromedia flash.

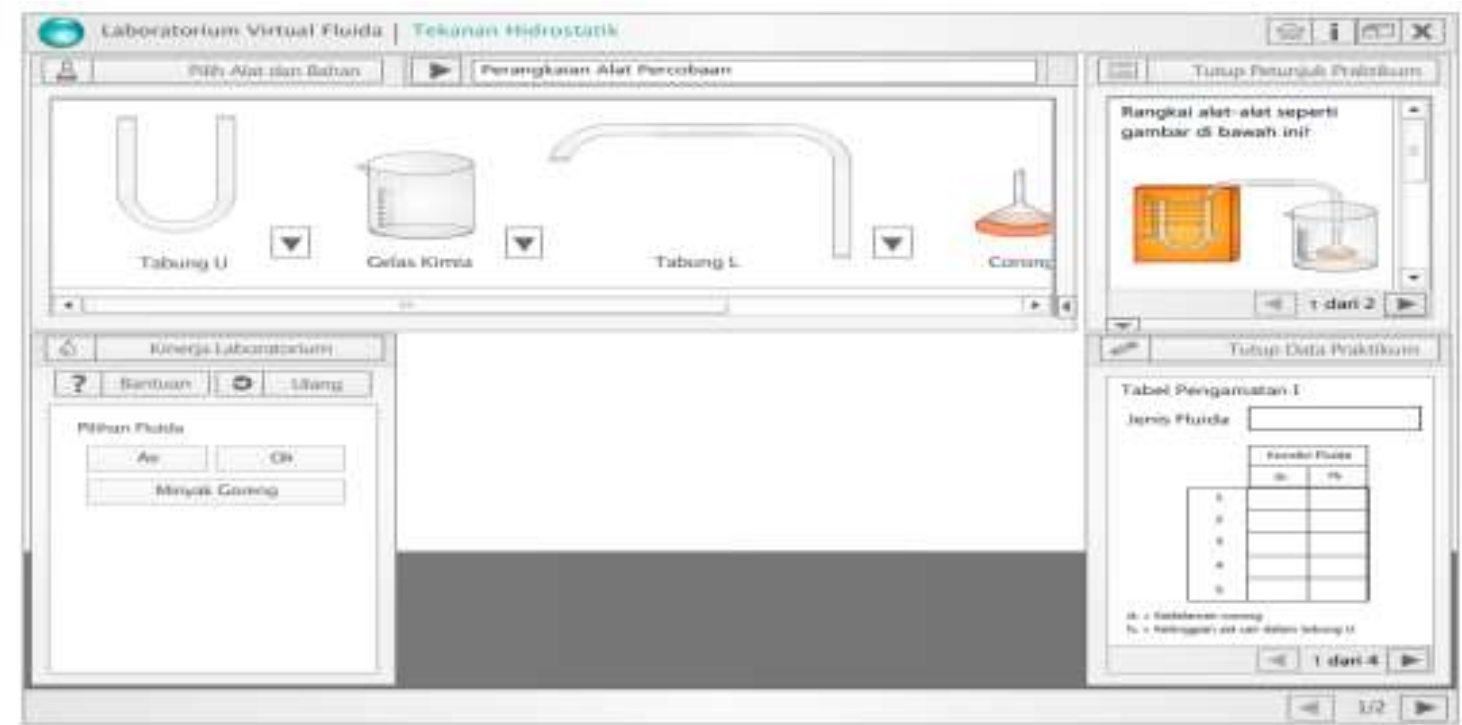

Gambar 3. Laboratorium Virtual Fluida Statis Untuk Mahaiswa Calon Guru Matematika

Penggunaan Virtual laboraotroim ternyata lebih mampu meningkatkan keterampilan berpikir kritis untuk mahasiswa calon guru matematika. Pada gambar 4 tersaji kegiatan praktikum virtual laboratorium secara mandiri yang dilakukan diluar jam perkuliahan fisika dasar. Hal ini disebabkan mahasiswa diajak mencari konsep melalui percobaan secara virtual sehingga mereka mendapatkan pemahaman konsep bukan melalui transfer of knowladge dari dosen tapi dari kegiatan memahami fenomena fisis melalui percobaan virtual.

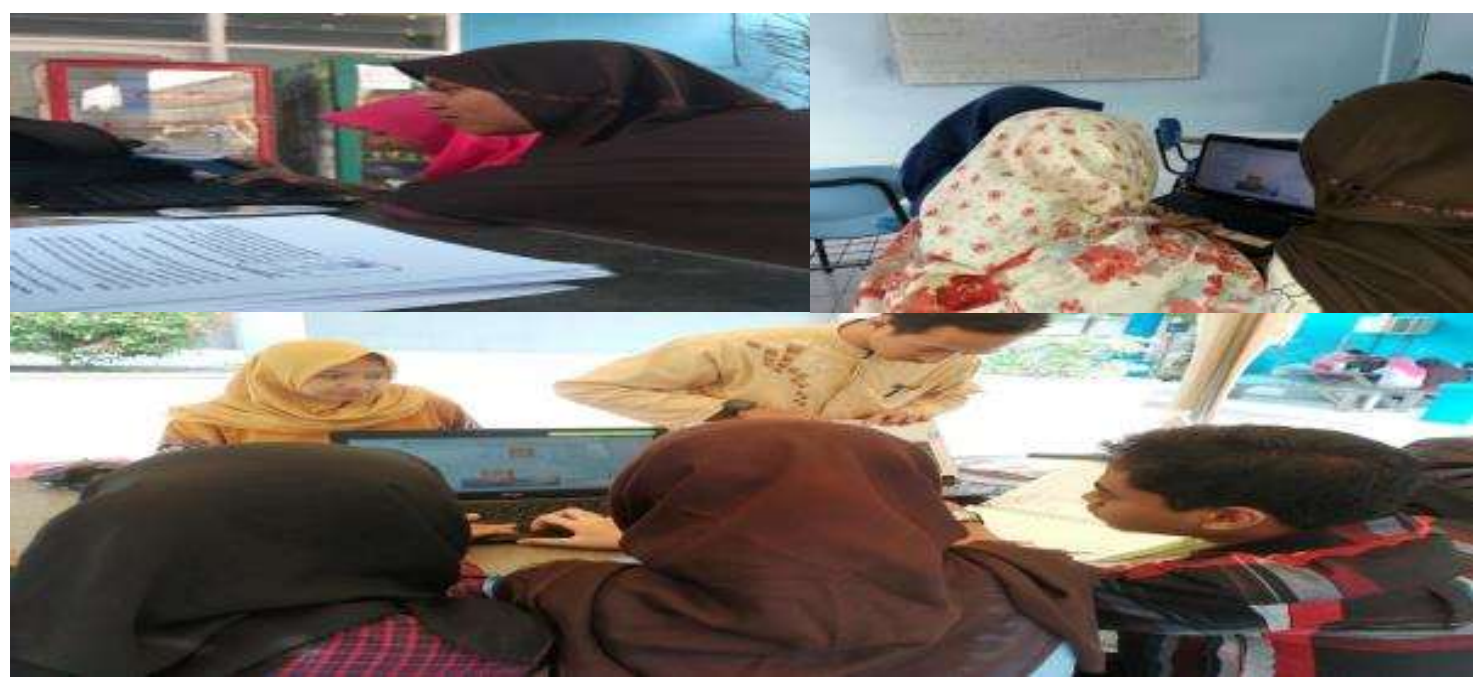

Gambar 4. Implementasi Virtual Laboratorium Untuk Calon Guru matematika 


\section{SIMPULAN DAN SARAN}

Berdasarkan data dan analisis hasil penelitian yang telah dilakukan tentang perkuliahan fisika untuk calon guru matematika menggunakan praktikum virtual untuk meningkatkan keterampilan berpikir kritis mahasiswa dapat disimpulkan bahwa:

1. Pembelajaran berbasis praktikum virtual bagi mahasiswa calon guru matematika secara signifikan dapat lebih meningkatkan keterampilan berpikir kritis mahasiswa calon guru matematika.

2. Pada umumnya, mahasiswa memberikan tanggapan positif terhadap pembelajaran menggunakan praktikum virtual

Perlu dilakukan penelitian lebih mendalam mengenai peran matakuliah fisika dalam membekali kompetensi mahasiswa calon guru matematika. Variable terikat yang diteliti haruslah yang lebih bersifat spesifik ke kompetensi calon guru matematika, misalnya kemamuan konstruksi model matematis. Saat ini peneliti sedang mengembangkan penelitian ini dalam karya tulis selanjutnya.

\section{DAFTAR RUJUKAN}

Anderson, L. W., et al. 2001. A Taxonomy for Learning, Teaching and Assessing : A Revision of Bloom's Taxonomy of Educational Objectives. NY: Addison Wesley Longman Inc

Abdullah, S \& Adilah, S. (2008). The Effects of Inquiry-Based Computer Simulation with Cooperative Learning on Scientific Thinking and Conceptual Understanding of Gas Laws. Eurasia Journal of Mathematics, Science \& Technology Education. 4(4): 387-398.

Fraenkel, J.R. \& Wallen, N.E. 2007. How To Design And Evaluate Research In Education, 6th Edition. Singapore: McGraw-Hill

Gustrial. 2009. Penggunaan Media Simulasi Virtual Pada Pembelajaran dengan Pendekatan Konseptual Interaktif untuk Meningkatkan Pemahaman Konsep dan Meminimalkan Kuantitas Miskonsepsi pada Materi Kalor. Tesis Magister pada SPS UPI Bandung : tidak diterbitkan.

Jaakkola, T., \& Nurmi, S. (2007). Fostering elementary school students' understanding of simple electricity by combining simulation and laboratory activities. Journal of Computer Assisted Learning (2008), 24, 271-283.

Kurniawan, Dede Trie. (2012). Model pembelajaran berbasis masalah interaktif pada konsep fluida statis untuk meningkatkan penguasaan konsep dan keterampilan proses sains siswa kelas XI. Bandung. Tesis. UPI.

Kurniawan, Dede Trie. (2013).Analisis kesulitan perkuliahan fisika dasar dan profil kecerdasan majemuk mahasiswa calon guru matematika tingkat I FKIP Unswagati Cirebon 2014. Jurnal LOGIKA UNswagati Cirebon

Maryanti, S. 2012. Pembelajaran superkelas pisces berbantuan praktikum virtual dalam 
mengembangkan keterampilan berpikir kritis dan sikap ilmiah mahasiswa. Tesis Magister SPS UPI : tidak diterbitkan

Oktavianti, Erwina.(2012). Penerapan Model Pembelajaran Inkuiri dengan pendekatan multiple representasi pada topik fluida statis untuk meningkatkan kemampuan kognitif dan keterampilan berpikir kritis. Thesis Magister SPs UPI : Tidak di terbitkan

Oral, I., Bozkurt, E., \& Guzel, H. (2009). The Effect of Combining Real Experimentation With Virtual Experimentation on Students' Success. World Academy of Science, Engineering and Technology 542009.

Putra, P.D.A.2015. Pengembangan Sistem E-Learning untuk meningkatkan keterampilan berpikir kritis mahasiswa pendidikan fisika. Jurnal Fisika Indonesia, No 55 Vol XIX edisi Mei 2015. ISSN : 1410-2994

Yang, Kun-Yuan \& Jia-Sheng Heh. (2007). The Impact of Internet Virtual Physics Laboratory Instruction on the Achievement in Physics, Science Process Skills and Computer Attitudes of 10th-Grade Students. Journal Scince Education Technology. 16: 451-461.

Zacharia, Z. C. (2006). Comparing and combining real and virtual experimentation: an effort to enhance students' conceptual understanding of electric circuits. Journal of Computer Assisted Learning (2007), 23, 120-132. 